\title{
Mechanical Performance of Actuators in an Active Orthosis for the Upper Extremities
}

\author{
Roland Wiegand, Bastian Schmitz, Christian Pylatiuk, and Stefan Schulz \\ Institute for Applied Computer Science, Karlsruhe Institute of Technology, 76344 Karlsruhe, Germany \\ Correspondence should be addressed to Roland Wiegand, roland.wiegand@kit.edu
}

Received 31 May 2011; Revised 25 August 2011; Accepted 30 September 2011

Academic Editor: Tetsuya Mouri

Copyright ( $) 2011$ Roland Wiegand et al. This is an open access article distributed under the Creative Commons Attribution License, which permits unrestricted use, distribution, and reproduction in any medium, provided the original work is properly cited.

\begin{abstract}
The aim of the project OrthoJacket is to develop a lightweight, portable, and active orthosis for the upper limps. The system consists of two special designed fluidic actuators which are used for supporting the elbow function and the internal rotation of the shoulder. A new design of flexible fluid actuator (FFA) is presented that enables more design options of attaching parts, as it is allowed by conventional actuators with a stationary centre of rotation. This advantage and the inherent flexibility and the low weight of this kind of actuator predestined them for the use in exoskeletons, orthoses, and prostheses. The actuator for the elbow generates a maximum torque of $32 \mathrm{Nm}$; the internal rotation is supported with $7 \mathrm{Nm}$. Both actuators support the movement with up to $100 \%$ of the necessary power. The shells for the arm and forearm are made of carbon reinforced structures in combination with inflatable cushions.
\end{abstract}

\section{Introduction}

Most of the 300,000 persons in Europe who suffer from a spinal cord injury have a lesion between the fourth and the fifth vertebra [European Multicenter Study of Spinal Cord Injury; http://www.emsci.org/]. These patients often have limited remaining functions of the shoulder and elbow [1] but cannot use them in everyday life, as the strength is insufficient to autonomously execute activities. For the assistance of people with a tetraparesis or tetraplegia, various systems exist $[2,3]$. They focus on stationary rehabilitation and therapy with the assistance of medical staff [4-6]. The OrthoJacket project is aimed at developing a lightweight, wearable, inconspicuous, and mobile support system for the upper extremities. The system was built to support the patients and to give them more autonomy and independence in everyday life. For this purpose, the movements of the upper extremities are supported actively, and the joints are protected by an orthosis. This system is not only developed for training purposes, but it also has to be usable in everyday life. Therefore, it must be a mobile system, contrary to other rehabilitation systems $[7,8]$. The orthosis will be more accepted and used by the patients, if it is uncomplicated and reliable in operation.
Moreover, wearing and use of the system should be possible without attracting attention. As the resulting functional restrictions vary for every patient, the system consists of different self-sufficient functional parts. Consequently, it can be adapted easily to the individual needs of different patients. OrthoJacket consists of three parts that can be used alone and in combination with the other parts (see Figure 1) [9-11].

(i) The movement of the wrist and the grasping function of the hand are achieved by functional electrical stimulation (FES).

(ii) At the elbow, the system consists of a lightweight active orthosis that is partly integrated in a jacket and a flexible fluidic actuator $[12,13]$. The shells of the orthosis are made of an inflatable cushion, and a support structure is made of carbon fiber.

(iii) The shoulder function is supported by a linear axle system. It is attached to the wheelchair and actuated by two stepper motors.

The orthosis will be controlled by electromyography measurements $[14,15]$ at different, voluntarily contractible muscles, or by a joystick which is attached to the shoulder 


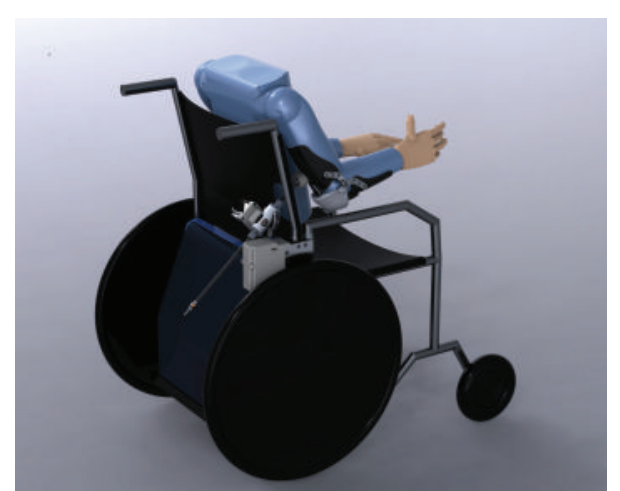

FIgURE 1: CAD model of the OrthoJacket.

or the neck. These two types of control mechanisms do not provide a nominal value, only a direction of movement and perhaps a speed can be obtained from these signals [16]. This paper focuses on the actuators for the support of the elbow function and the internal rotation, adduction, and anteversion of the shoulder and the inflatable shell structure.

\section{Methods}

The first tests of the system were made with healthy subjects. In these tests, it was determined how large the range of movement is for persons of different sizes. The effect of limbs of varying weight on system operation was also evaluated. The three individuals were able to move their upper extremities unrestrictedly. Their weights ranged from 63 to $95 \mathrm{~kg}$, and their size varied between 1.84 and $1.92 \mathrm{~m}$. The age was between 24 and 29. For comparison, the measure of the $50 \%$ male person from the Man-Systems Integration Standards NASA-STD-3000 [17] is also given in Table 1.

In a multibody simulation, the moments required for the movement of the patient's upper extremities were determined. This simulation consisted of two different actions. One was putting a glass to the mouth and drinking, the other action consisted in eating with a fork. In the simulation, weights and inertia of each segment of the upper extremities were considered. The friction of the joints depends on physical conditions of the patients and, hence, was not considered in the simulation. Instead, the weight of the fork and glass was multiplied by a safety factor, so that the items had a higher weight in this case than in reality (fork $0,15 \mathrm{~kg}$, glass $0,75 \mathrm{~kg}$ ) [18]. Based on the multibody simulation results, a minimum torque was defined, which is necessary for the movement of the arm. This minimum torque amounts to $7 \mathrm{Nm}$ in the range from 0 to $90^{\circ}$ and $5 \mathrm{Nm}$ from 90 to $120^{\circ}$. In the article "A study of the external forces and moments at the shoulder and elbow while performing everyday tasks" [19], the joint moments of healthy individuals in ten different everyday tasks were determined. In this paper, a maximum torque of $5 \mathrm{Nm}$ for the elbow is indicated. Due to the uncertainty in the weight of the patient and the joint friction, our maximum has a higher value. For the shoulder, torques in the range of $30 \mathrm{Nm}$ are required. (Adduction, anteversion about $30 \mathrm{Nm}$ and for the internal rotation about $3.5 \mathrm{Nm}$ )
TABLE 1: Data of the three subjects.

\begin{tabular}{ccccc}
\hline \multicolumn{2}{l}{ Patient Weight $[\mathrm{kg}]$} & Size [m] & Arm weight $[\mathrm{kg}]$ & $\begin{array}{c}\text { Upper arm } \\
\text { circumference } \\
{[\mathrm{m}]}\end{array}$ \\
\hline 1 & 63 & 1.84 & 2.2 & 0.23 \\
2 & 84 & 1.88 & 3.8 & 0.32 \\
3 & 95 & 1.92 & 5.2 & 0.33 \\
\hline $50 \%$ & 82.2 & 1.697 & 4.48 & 0.312 \\
\hline
\end{tabular}

TABle 2: Data sheet of the elbow actuator.

\begin{tabular}{lcc}
\hline Weight & 33.2 & $\mathrm{~g}$ \\
Air volume & $16 \times 1286=20576$ & $\mathrm{~mm}^{3}$ \\
Air volume & 0.020576 & $\mathrm{~L}$ \\
\hline Thickness at $0 \mathrm{kPa}$ & 17 & $\mathrm{~mm}$ \\
Thickness at $100 \mathrm{kPa}$ & 180 (mechanical stop) & $\mathrm{mm}$ \\
Angle & 130 (mechanical stop) & $\circ$ \\
\hline Operating pressure & 200 to 300 & $\mathrm{kPa}$ \\
Maximum pressure & 400 & $\mathrm{kPa}$ \\
Burst pressure & 960 & $\mathrm{kPa}$ \\
\hline Assembly & 16 Chambers & \\
Area per chamber & 1737 & $\mathrm{~mm}^{2}$ \\
\hline
\end{tabular}

These values are higher than in [19], because the additional weight of the orthosis must be moved, too.

2.1. Design of the Elbow Actuator. As a drive, a flexible fluid actuator is used, because these actuators have a high power density, a small weight, inherent compliance, and they ensure safety [20]. The elbow orthosis is moved by an FFA which will be integrated in the orthosis. As the actuator is built of several chambers made of film, the geometry can be adapted easily to the space available. The newly designed fluidic actuator consists of 16 arched and interconnected chambers (see Table 2). It assumes the shape of a hemisphere under pressure. At each end of a chamber, a strap is attached for mechanical guiding of the actuator. The straps are connected with each other and with the joint axle. Hence, the actuator can be integrated easily in a piece of clothing and hardly interferes with the natural aspect. In order to minimize additional loading of the joint by the actuator, the rotation axis of the orthosis should be positioned at the same point and with the orientation corresponding to the rotation axis of the human elbow joint. The actuator is made of a fabric-reinforced polyurethane film. The cloth is a tightly woven fabric made of polyamide with plain weave ( $235 \mathrm{dtex})$, which is laminated on both sides with a layer of thermoplastic polyurethane. This fabricreinforced plastic film has a tensile strength of about $200 \mathrm{~N}$ and a thickness of 400 micron. From this tissue, individual foil segments are punched and connected in a multistage high-frequency welding process. For flexion, the actuator is pressurized with an overpressure of up to $400 \mathrm{kPa}$. Extension requires a smaller torque, because it is not necessary to overcome gravity. Consequently, $90 \mathrm{kPa}$ partial vacuum is sufficient to move the forearm back to the $0^{\circ}$ position. Exact 


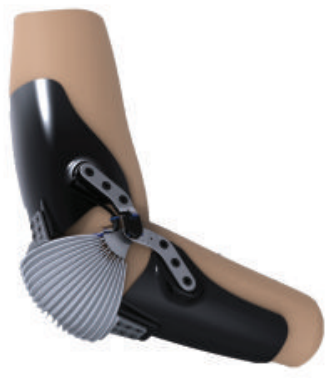

FIGURE 2: Elbow orthosis with shells made of ABS.

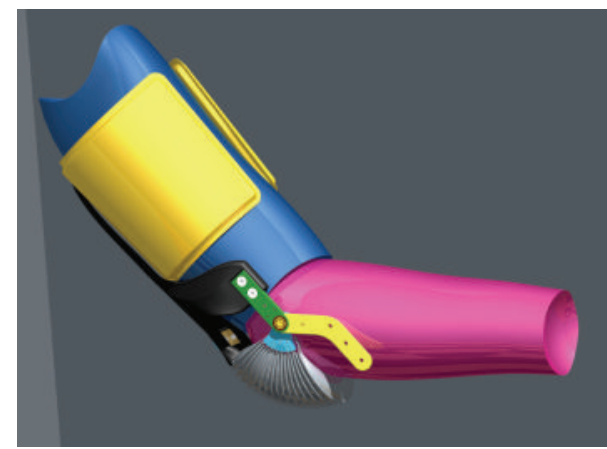

FIGURE 3: Inflatable shell structure.

pressure adjustment between -90 and $400 \mathrm{kPa}$ is accomplished by a proportional valve (modified Festo MPPE 3-1 1/8-6-010-B). Together with the pump and the storage tank for compressed air, it is located in a sound-proof container below the seat of the wheelchair. For the first prototype, the shells were made of ABS plastic, which was shaped as desired by a rapid prototyping process (see Figure 2 ). The structure of the heavily loaded segments was reinforced with carbon fiber. For the measurement of the elbow joint angle, a digital angle sensor based on the Hall effect is used. It determines the current angle with a resolution of 12 bit.

2.2. Inflatable Shell Structure. In conventional, passive orthoses, the arm of the user is fixed in a half shell of a thermoplastic or fiber-composite material. The fasteners for the arm are made of a combination of a Velcro fastener and elastic straps. Depending on how strong the orthosis should be attached to the body of the patient, the tapes are prestressed. In the case of an active orthosis, the elbow and shoulder actuators support the patient with up to $30 \mathrm{Nm}$, as a result of which the shell must be attached securely to the upper extremity. If an active orthosis attached firmly to the arm with straps, the blood flow is obstructed and also the skin is severely squeezed. The disturbed blood circulation [21] of the upper extremities from quadriplegics will be further complicated by this attachment method. To avoid this effect, an inflatable shell structure has been developed. It distributes the force over a larger area than conventional

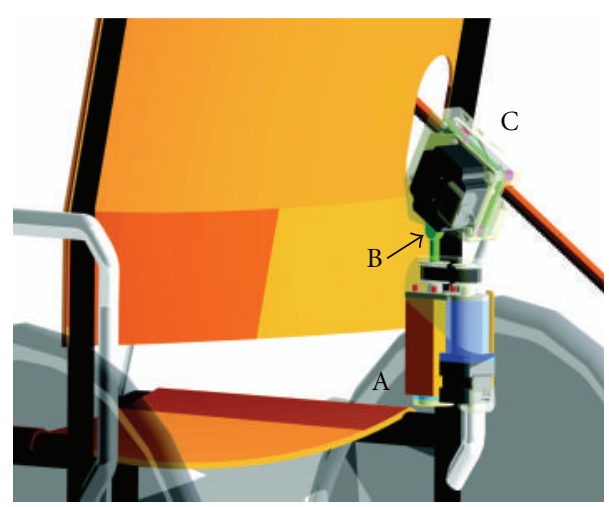

FIGURE 4: Shoulder supports structure mounted on the wheelchair A: vertical axle, B: passive joint, C: linear unit.

tapes. Additionally, its rigidity and thickness are adjustable via the air pressure (see Figure 3, yellow part in the CAD model). Consequently, the air pressure in the OrthoJacket can be reduced at recovery time, and, thus, the skin is given time to relax. This new shell structure consists of a rugged composite material structure that connects the two supporting points of the elbow joint and the support points of the actuators. Additionally, this structure extends along the longitudinal axis of the upper or lower arm and is used for constant application of force into the body (see Figure 3, black stripe in the CAD model). When pressurized, the inflatable support structure assumes a semicircular shape and surrounds the arm independently. It is composed of two 300 or 325 by $100 \mathrm{~mm}$ large rectangles which are welded together at the perimeter. The surfaces of the two rectangles are connected by 27 stripes. This prevents the structure from deforming. Inside, the shell is lined by thin-layer upholstery. Outside, the orthosis is covered by two layers of fabric. An important point in the development of the shell structure was to create the possibility to dress and undress the orthosis easily. As the user of the system cannot participate actively in the dressing process, the system has to be easy to attach to the upper extremities. This is achieved by a zipper that runs along the longitudinal axis of the arm. Thus, the arm can be positioned on the unfolded orthosis, and the zipper can be closed. Then, the elbow is bent to make sure that the elbow joint is at the same place as the axle of the elbow support structure. Only then will the support structure be inflated and connect the OrthoJacket with the patients arm.

2.3. Shoulder Support Structure. The system to support the shoulder consists of a vertically oriented axis of rotation that allows for the rotation of the shoulder. Adduction and anteversion are achieved by an actively driven linear axle which acts in the middle of the upper arm, thus, lifting the arm (see Figure 4). The angle between the linear axle and the horizontal axle is located above a passive rotational degree of freedom. By using a kinematic unit with a linear axle, the problem of the nonstationary pivot point of the shoulder joint is solved. With this solution, it is possible to support the full shoulder function with only two drivers, with the control of the system being facilitated for the patient. 
According to the simulation, the maximum torque required for adduction, anteversion, and rotation is about $30 \mathrm{Nm}$ (adduction, anteversion) and about $3.5 \mathrm{Nm}$ for the rotation. With this stepper motor/gearbox combination, movements in the angle range of 0 to $80^{\circ}$ for adduction and anteversion and -30 to $+30^{\circ}$ for rotation are possible. Restrictions may be due to the anatomy of the user and must be considered. Small inaccuracies (up to $10 \mathrm{~mm}$ ) in the positioning of the patient relative to the shoulder system are no problem. When using a shoulder support system $\left(S^{3}\right)$ with three actuators arranged around the shoulder, it must always be ensured that the center of rotation of the shoulder and the support structure are exactly at the same position.

The vertical axle of the $S^{3}$ consists of a stepper motor. It drives a planetary gear with a reduction ratio of $1: 49$. This combination generates about $4.5 \mathrm{Nm}$ of torque. Using a belt with a slip clutch in the driven gear, the vertical axle is moved. At the end of the vertical axle (see Figure 4, A), the linear unit (see Figure 4, C) is mounted with a passive degree of freedom (see Figure 4, B). The linear unit consists of a stepper motor with $0.65 \mathrm{Nm}$ torque and a two-stage spur gear unit with a reduction ratio of $1: 4$. The linear axle consists of an aluminum profile onto which a rack made of steel is mounted. The linear axle of the stressed segments is guided by ball bearings. Lateral guiding is achieved by Teflon journal bearings. The active and passive rotational degrees of freedom are monitored by absolute position encoders. The linear axle has to perform a reference run at the beginning. The current position is identified by counting the steps of the stepper motor. Internal rotation is achieved by another fluid actuator (Figure 5). It is mounted at the top of the linear axle and allows bending of $\pm 45^{\circ}$. By an optimized mounting position, an angle from 0 to $90^{\circ}$ between the linear axle and the forearm can be set.

The actuator also supports the anteversion movement. It consists of six stacked, circular segments; each of them is divided into eight separate chambers (see Table 3). The chambers of stacked segments are connected with each other, such that the actuator consists of eight independent controllable subactuators. At the top and bottom segment, a connecting plate is mounted. These two plates are connected with a string of high-strength yarn that allows for lateral tilting but limits the maximum height of the actuator. By varying the air pressure in the individual subactuators, it is possible to generate movements to the left, right, top, and bottom. With a special sequence of pressure rises, even rotational motions are possible. The actuator has a diameter of $65 \mathrm{~mm}$; the single chambers are circular sectors with an opening angle of $45^{\circ}$. The height of the actuator is limited to $35 \mathrm{~mm}$. As the actuator has no fixed rotation axles, the two tilt angles are determined by two geomagnetic field sensors. These sensors deliver a vector with three components, one for each spatial direction. The value corresponds to the strength of the magnetic field which is parallel to the direction of the vector components. It is possible to determine the angular position of the sensor relative to the Earth's magnetic field. Such a sensor is attached to each of the two connecting plates. From the difference of the two vectors, the angle between the two connection plates can be determined. Due to the small distance

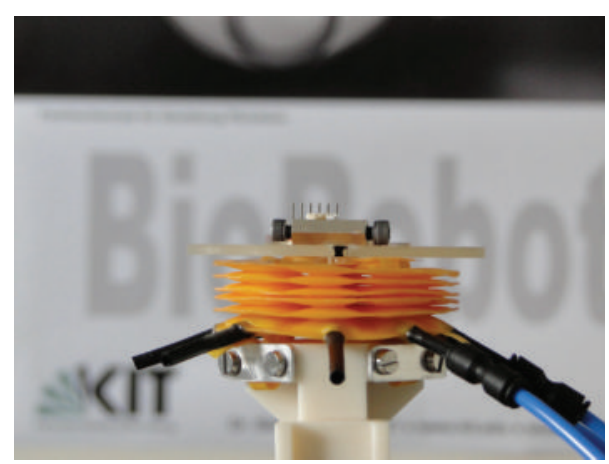

FIgURE 5: Actuator for internal rotation without pressure.

TABle 3: Data sheet of the 2D actuator.

\begin{tabular}{lcc}
\hline Weight & 22 & $\mathrm{~g}$ \\
Volume & $8 \times 4.5$ & $\mathrm{~mL}$ \\
Nominal area of a chamber & 295 & $\mathrm{~mm}^{2}$ \\
\hline Diameter & 65 & $\mathrm{~mm}$ \\
Nominal height & 10 & $\mathrm{~mm}$ \\
Max. height & 45 & $\mathrm{~mm}$ \\
\hline Operating pressure & 600 & $\mathrm{kPa}$ \\
Max. pressure & 1100 & $\mathrm{kPa}$ \\
Assembly & 6 segments, each & \\
& with 8 individual & \\
& chambers & \\
\hline
\end{tabular}

between the two sensors, possible variations of the geomagnetic field will always affect both sensors, as a result of which the relative position to each other is determined correctly. The actuator is controlled by a proportional valve (Festo MPPE 1/8-6-010-B 3-1) which is connected in series with eight shift valves (Bürkert 6104). The shift valves are used as a switch connecting the proportional valve to one of the eight chambers. This actuator is controlled directly by the patient. The pressure in the chamber is increased or decreased until the desired angle of the support structure is reached. With the two geomagnetic field sensors, the position of the orthosis is monitored. In addition, the two angles needed to adjust the position of the hand are controlled. Furthermore, a pressure limit is implemented to detect a locked drive.

\section{Results}

3.1. Elbow Actuator. The newly designed elbow actuator is able to support the elbow with up to $32 \mathrm{Nm}$. The burst pressure of one actuator chamber is $970 \mathrm{kPa}$. Figure 7 shows the actuator providing the torques required for a safe operation of the orthosis. The required pressure range for operation is between 200 and $300 \mathrm{kPa}$ (Figure 6). In this range, the torque curve is approximately linear. Using the first prototype of this active orthosis, the step response of the control path consisting of valve, elbow actuator, and orthosis was determined. To make the test as real as possible, the brace was loaded with a cast resin forearm with hand 


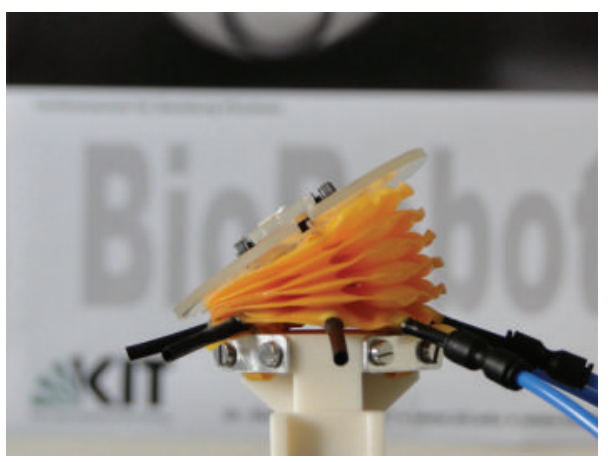

FIGURE 6: Actuator for internal rotation, 3 chambers with a pressure of $300 \mathrm{kPa}$.

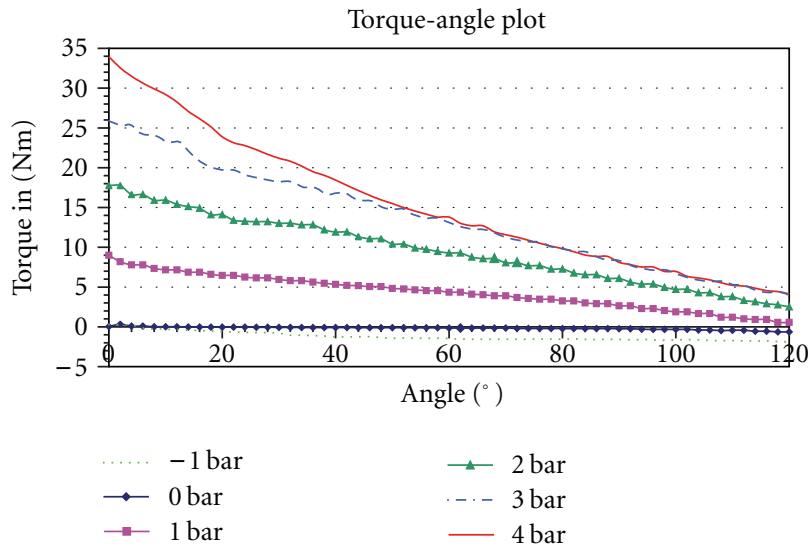

Figure 7: Torque plot of the elbow actuator.

$(1.61 \mathrm{~kg})$. Compressed air is supplied via a polyurethane tubing with an inner diameter of $4.2 \mathrm{~mm}$, followed by a tube which has an inner diameter of 1.7 or $2.7 \mathrm{~mm}$. The tubing of $1.7 \mathrm{~mm}$ is flexible and can be integrated inconspicuously in the jacket. The higher flow resistance of the $1.7 \mathrm{~mm}$ tube causes lifting of the forearm in 0.9 seconds. For the tube with the internal diameter of $2.7 \mathrm{~mm}$, the lifting time only is about half a second (see Figure 8$)$. The step response $(0-150 \mathrm{kPa})$ of the actuator/valve combination has a reaction time of 0.1 seconds. Then, it almost behaves similarly to a PT1 element. The slight decline of the $1.7 \mathrm{~mm}$ tube in the upper part of the plot results from a kink in the tube. The control of the valve and the recording of the sensor data are performed with a USB-connected card from National Instruments on a Windows PC with LabVIEW.

3.2. Shoulder Support Structure. The rotation axle and the linear axle produce a torque of $4.5 \mathrm{Nm}$ and a maximum force of $210 \mathrm{~N}$. The maximum torque of the FFA at the top of the linear axle is $7 \mathrm{Nm}$. Other data of the FFA actuator can be found in Table 3. With this fluid actuator, an angle torque plot was recorded (see Figure 9). These curves are linear over a wide area, only for large angles are they significantly increased. The discontinuity at $0^{\circ}$ is caused by the exchange of the chambers. Using this actuator, step response was recorded as it was done for the elbow actuator. The test

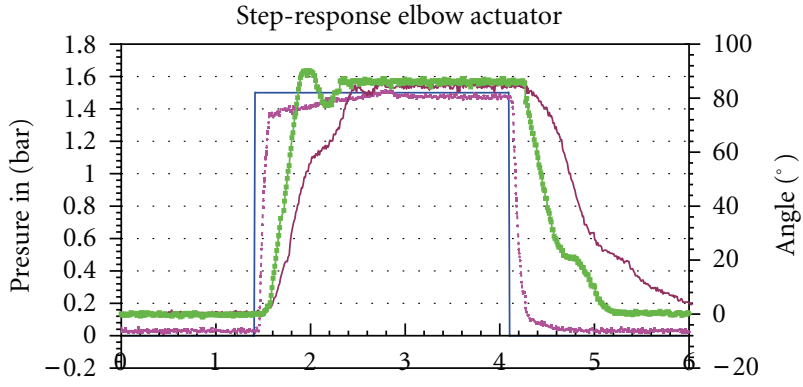

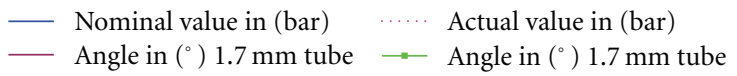

Figure 8: Step response of the elbow actuator with a 1.7 and a $2.7 \mathrm{~mm}$ tube and $150 \mathrm{kPa}$ pressure.

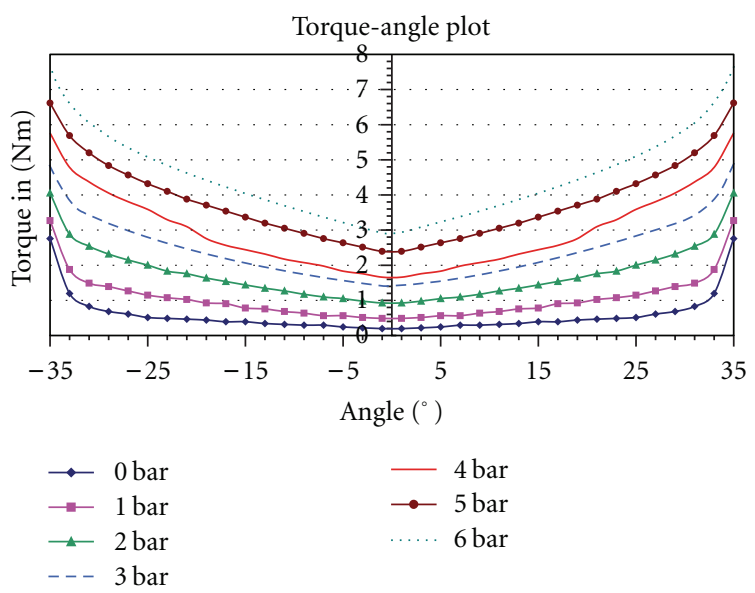

FIgURE 9: Torque plot of the actuator for internal rotation.

assembly of the system corresponds to the mounting position in the wheelchair. The proportional valve is linked to a tube of $4.2 \mathrm{~mm}$ internal diameter. After $150 \mathrm{~mm}$ of $2.7 \mathrm{~mm}$ tubing, one of the shift valves controlling the individual chambers is connected. These are directly connected to the actuator. Measured values are recorded with the same hardware as used for the step response of the elbow actuator. The response time of the proportional valve is 0.1 seconds; the switching time of the shift valve is in the range of 14 or $18 \mathrm{~ms}$ (open and close, value from the data sheet). The time necessary to inflate one of the eight chambers of the actuator with $300 \mathrm{kPa}$ is about 0.25 seconds (see Figure 10), and a complete filling process (open shift valve, set pressure with the proportional valve, close shift valve) requires 0.37 seconds to reach the proper air pressure. The time until all eight chambers have the desired air pressure is 2.96 seconds.

3.3. Evaluation of the Movement Space. The real ranges of movement of the OrthoJacket were determined for five subjects of different sizes and weights (see Table 4). The maximum angle of every joint reached by the orthosis was identified. Several different stopping criteria were specified, some were set by the mechanics, others by the subject 


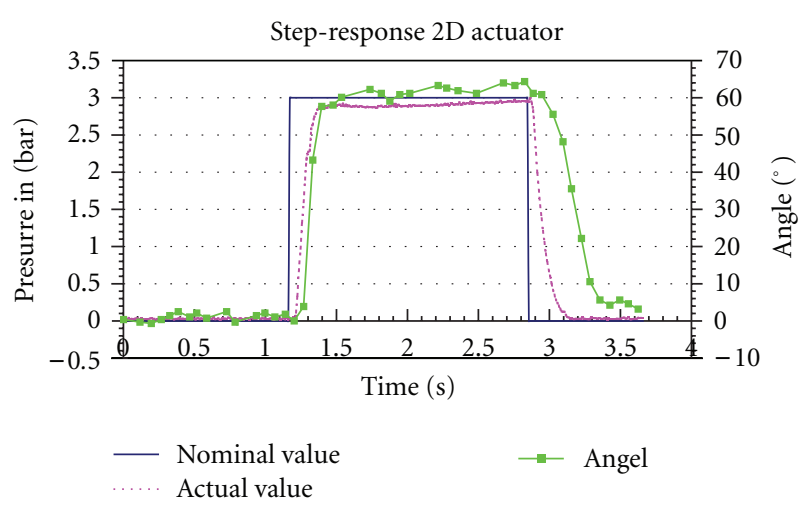

FIGURE 10: Step response of the actuator for internal rotation with $300 \mathrm{kPa}$ pressure.

TABLE 4: Body dimensions of the subjects.

\begin{tabular}{ccccc}
\hline Subject & $\begin{array}{c}\text { Weight } \\
\text { in [kg] }\end{array}$ & $\begin{array}{c}\text { Size in } \\
{[\mathrm{mm}]}\end{array}$ & $\begin{array}{c}\text { Weight of the } \\
\text { upper extremity } \\
\text { in }[\mathrm{kg}]\end{array}$ & $\begin{array}{c}\text { Circumference } \\
\text { of the upper } \\
\text { arm in [mm] }\end{array}$ \\
\hline 1 & 63 & 1840 & 2200 & 230 \\
2 & 84 & 1880 & 3800 & 320 \\
3 & 95 & 1920 & 5200 & 360 \\
4 & 77 & 1640 & 3500 & 280 \\
5 & 68 & 1780 & 3400 & 275 \\
\hline
\end{tabular}

TABLE 5: Description of the stopping criteria.

\begin{tabular}{cl}
\hline Stopping criteria & Description \\
\hline 1 & Drive is mechanically blocked \\
2 & Drive has not enough power \\
3 & Subject does not feel comfortable \\
4 & Subjects and mechanics collide \\
5 & Enough for everyday tasks \\
\hline
\end{tabular}

(see Table 5). The angle of the elbow was limited to $90^{\circ}$. In this test, only the elbow orthosis and the two electrically driven axles of the shoulder system were used.

The first tests of the mechanical parts of the system were made with healthy subjects. Healthy people are able to give better feedback about the function and comfort of the system. The angular ranges for anteversion and adduction of about 75 and $45^{\circ}$ are in the expected range. The system works as expected (see Table 6). None of the three subjects felt uncomfortable when using the orthosis. For patient three, the traverse path of the linear axle was not sufficient to further lift the arm. The collision of the system and the arm rest of the wheelchair can be prevented by choosing another wheelchair or by some modifications of the current one.

A second test was made with a tetraplegic patient. The patient was paralyzed below $\mathrm{C} 4$, and random movement of the biceps was very difficult. Controlled activation of the triceps was impossible. In this test, only the elbow orthosis was used. With the orthosis, the patient was able to move his arm from about 10 to $90^{\circ}$. The elbow orthosis was controlled
TABLE 6: Results of the test.

\begin{tabular}{cccc}
\hline Patient & $\begin{array}{c}\text { Anteversion in }\left[{ }^{\circ}\right] \\
\text { (Stopping criteria) }\end{array}$ & $\begin{array}{c}\text { Adduction in }\left[^{\circ}\right] \\
\text { (Stopping criteria) }\end{array}$ & $\begin{array}{c}\text { Elbow in }\left[{ }^{\circ}\right] \\
\text { (Stopping criteria) }\end{array}$ \\
\hline 1 & $0(5)$ to $76(5)$ & $-20(4)$ to 29 (1) & $0(3)-90$ \\
2 & $0(5)$ to $71(5)$ & $-18(4)$ to $30(1)$ & $0(3)-90$ \\
3 & $0(5)$ to $51(3)$ & $-12(4)$ to $29(1)$ & $0(3)-90$ \\
4 & $0(5)$ to $79(3)$ & $-10(4)$ to $28(1)$ & $0(3)-90$ \\
5 & $0(5)$ to $77(3)$ & $-18(4)$ to 29 $(1)$ & $0(3)-90$ \\
\hline
\end{tabular}

by a shoulder joystick. In the patient test, it was checked how well the orthosis works on a tetraplegic patient and how reliably it can be moved. When the joystick signal exceeded a certain threshold value, the pressure in the actuator was increased slowly. When the signal dropped below the value, the movement stopped. The forearm was lowered according to the same principle, but with another threshold value. The results were satisfactory but also show that the patient first requires a training phase to eliminate acampsia of the joint and reduce the shortening of the sinews before the system can be used correctly.

\section{Conclusion}

The elbow orthosis and the shoulder system without the fluid actuator for internal rotation were evaluated on volunteers, and it was found that they are able to support the shoulder and elbow function in healthy persons with $100 \%$ of the required force. The torque plots indicate that patients with restricted motor functions can be supported with up to $100 \%$. Thanks to the flexibility of the fluidic actuators, the system is yielding and, in the case of spasticity, prevents high forces from being generated and decreases the risk of injury. The next steps are the integration of the FES system in the OrthoJacket and the installation of the control system. Additional tests with three tetraplegics will be performed. Grasping and release tests like those of [22,23] will be carried out with some modifications for our patient group (C4, C5, and maybe C6). These tests will take place in autumn 2011 at our project partner, the Orthopaedic University Hospital in Heidelberg, Germany.

\section{Acknowledgment}

This work was supported by the Federal Ministry of Education and Research (BMBF) within the funding program "Innovative aids," grant no. 01EZ-0774. The project Orthojacket is a health research cooperation between science and industry. The authors acknowledge support by Deutsche Forschungsgemeinschaft and the Open Access Publishing Fund of Karlsruhe Institute of Technology.

\section{References}

[1] A. Curt, M. E. Schwab, and V. Dietz, "Providing the clinical basis for new interventional therapies: refined diagnosis and assessment of recovery after spinal cord injury," Spinal Cord, vol. 42, no. 1, pp. 1-6, 2004. 
[2] A. Gupta and M. K. O’Malley, "Design of a haptic arm exoskeleton for training and rehabilitation," IEEE/ASME Transactions on Mechatronics, vol. 11, no. 3, pp. 280-289, 2006.

[3] R. J. Sanchez Jr., E. Wolbrecht, R. Smith et al., "A pneumatic robot for re-training arm movement after stroke: rationale and mechanical design," Proceedings of the 9th IEEE International Conference on Rehabilitation Robotics (ICORR '05), pp. 500 504, 2005.

[4] T. J. Engen, "Recent advances in upper-extremity orthotics," in The Advance in Orthotics, Edward Arnold, 1976.

[5] S. Balasubramanian, W. Ruihua, and M. Perez, "Rupert: an exoskeleton robot for assisting rehabilitation of arm functions," in Proceedings of Virtual Rehabilitation, pp. 163-167, 2008.

[6] K. Kadota, M. Akai, K. Kawashima, and T. Kagawa, "Development of power-assist robot arm using pneumatic rubbermuscles with a balloon sensor," in Proceedings of the 18th IEEE International Symposium on Robot and Human Interactive Communication (RO-MAN '09), pp. 546-551, 2009.

[7] J. Klein, S. J. Spencer, J. Allington et al., "Biomimetic orthosis for the neurorehabilitation of the elbow and shoulder (BONES)," Proceedings of the 2nd Biennial IEEE/RAS-EMBS International Conference on Biomedical Robotics and Biomechatronics (BioRob '08), pp. 535-541, 2008.

[8] I. Vanderniepen, R. Van Ham, M. Van Damme, R. Versluys, and D. Lefeber, "Orthopaedic rehabilitation: a powered elbow orthosis using compliant actuation," Proceedings of the IEEE International Conference on Rehabilitation Robotics (ICORR '09), pp. 172-177, 2009.

[9] S. Schulz, C. Pylatiuk, A. Kargov et al., "Design of a hybrid powered upper limb orthosis," in Proceedings of the World Congress on Medical Physics and Biomedical Engineering: Neuroengineering, Neural Systems, Rehabilitation and Prosthetics, pp. 468-471, September 2009.

[10] R. Rupp, U. Eck, O. Schill, M. Reischl, and S. Schulz, "Orthojacket an active fes-hybrid orthosis for the paralyzed upper extremity," in Proceedings of the Technically Assisted Rehabilitation (TAR '09), pp. 18-19, Berlin, Germany, 2009.

[11] C. Pylatiuk, A. Kargov, I. Gaiser, T. Werner, S. Schulz, and G. Bretthauer, "Design of a flexible fluidic actuation system for a hybrid elbow orthosis," in Proceedings of the IEEE International Conference on Rehabilitation Robotics (ICORR '09), pp. 167171, June 2009.

[12] A. Kargov, I. Gaiser, H. Klosek et al., "Design and evaluation of a pneumatically driven anthropomorphic gripper for service robotics," in Proceedings of the International Scientific-andTechnological Exhibition-Congress Mechatronics and Robotics, St. Petersburg, Russia, October 2007.

[13] I. Gaiser, A. Kargov, S. Schulz, and G. Bretthauer, "Enhanced flexible fluidic actuators for biologically inspired lightweight robots with inherent compliance," in Proceedings of the Workshop on Actuation \& Sensing in Robotics, Saarbrcken, Germany, October 2010.

[14] D. S. Andreasen, S. K. Allen, and D. A. Backus, "Exoskeleton with EMG based active assistance for rehabilitation," in Proceedings of the 9th IEEE International Conference on Rehabilitation Robotics (ICORR '05), vol. 2005, pp. 333-336, 2005.

[15] O. Schill, R. Rupp, C. Pylatiuk, S. Schulz, and M. Reischl, “Automatic adaptation of a self-adhesive multi-electrode array for active wrist joint stabilization in tetraplegic SCI individuals," in Proceedings of the IEEE Toronto International Conference on Science and Technology for Humanity (TIC-STH '09), pp. 708 $713,2009$.
[16] J. Rosen, M. Brand, M. B. Fuchs, and M. Arcan, "A myosignalbased powered exoskeleton system," IEEE Transactions on Systems, Man, and Cybernetics Part A, vol. 31, no. 3, pp. 210-222, 2001.

[17] DC 20546-0001 Washington, Man-Systems Integration Standards NASASTD-3000, vol. I, Public Communications Office NASA Headquarters Suite 5K39 Washington, DC 20546-0001, 1995.

[18] O. Schill, R. Wiegand, B. Schmitz et al., "OrthoJacket: an active FES-hybrid orthosis for the paralysed upper extremity," Biomedizinische Technik, vol. 56, no. 1, pp. 35-44, 2011.

[19] I. A. Murray and G. R. Johnson, "A study of the external forces and moments at the shoulder and elbow while performing every day tasks," Clinical Biomechanics, vol. 19, no. 6, pp. 586594, 2004.

[20] R. Wiegand, B. Schmitz, C. Pylatiuk, S. Schulz, and R. Rupp, "Fluidic actuation and sensors of the elbow joint in the hybrid orthosis othojacket," Biomedizinische Technik, vol. 55, no. s1, 2010.

[21] G. A. Zaech, Paraplegie-Ganzheitliche Rehabilitation, Karger, 2005.

[22] W. Michael, M. D. Keith, B. S. Kathryn Stroh Wuolle et al., "Development of a quantitative hand grasp and release test for patients with tetraplegia using a hand neuroprosthesis," Journal of Hand Surgery, vol. 19, no. 2, pp. 209-218, 1994.

[23] B. T. Smith, M. J. Mulcahey, and R. R. Betz, "Quantitative comparison of grasp and release abilities with and without functional neuromuscular stimulation in adolescents with tetraplegia," Paraplegia, vol. 34, no. 1, pp. 16-23, 1996. 

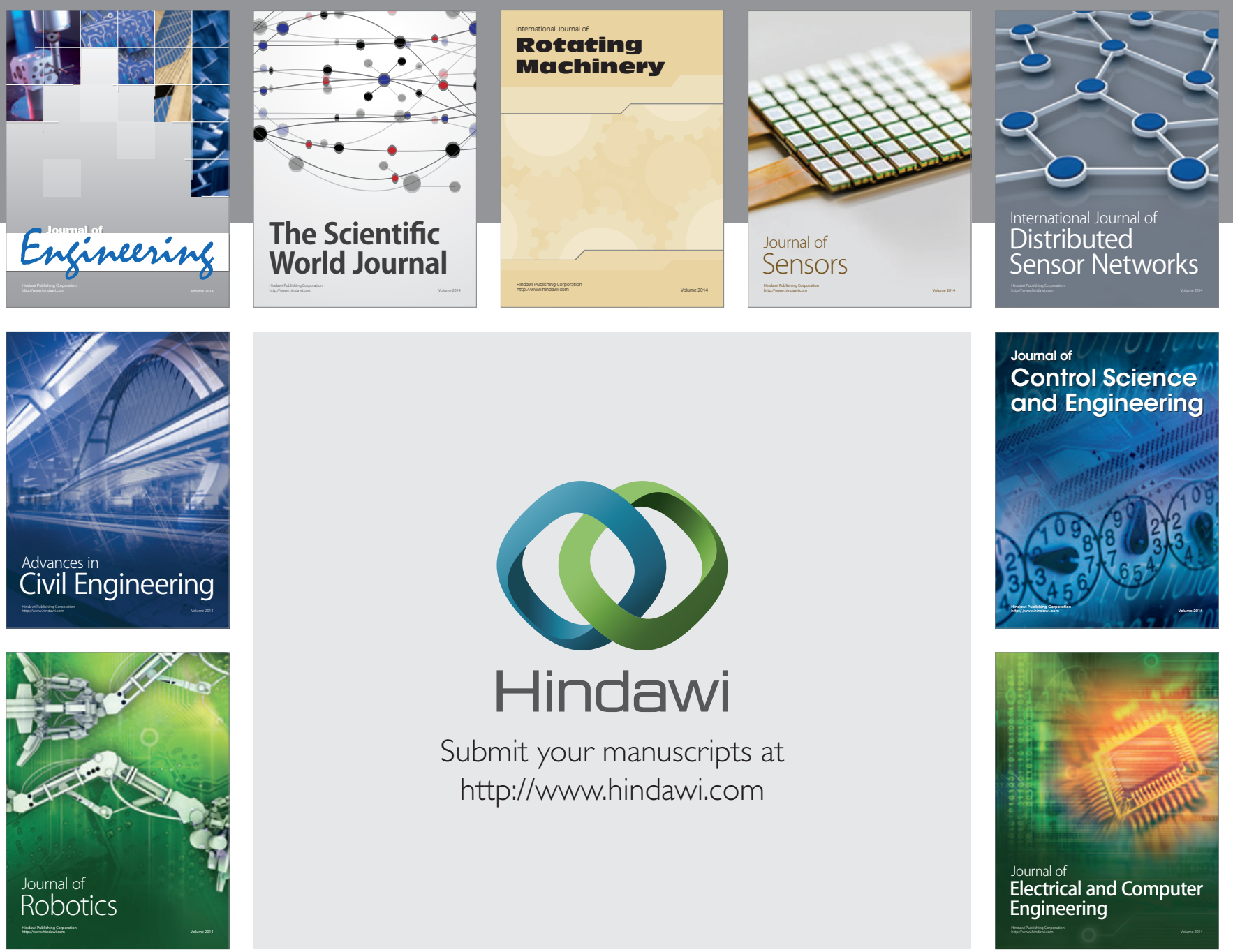

Submit your manuscripts at

http://www.hindawi.com
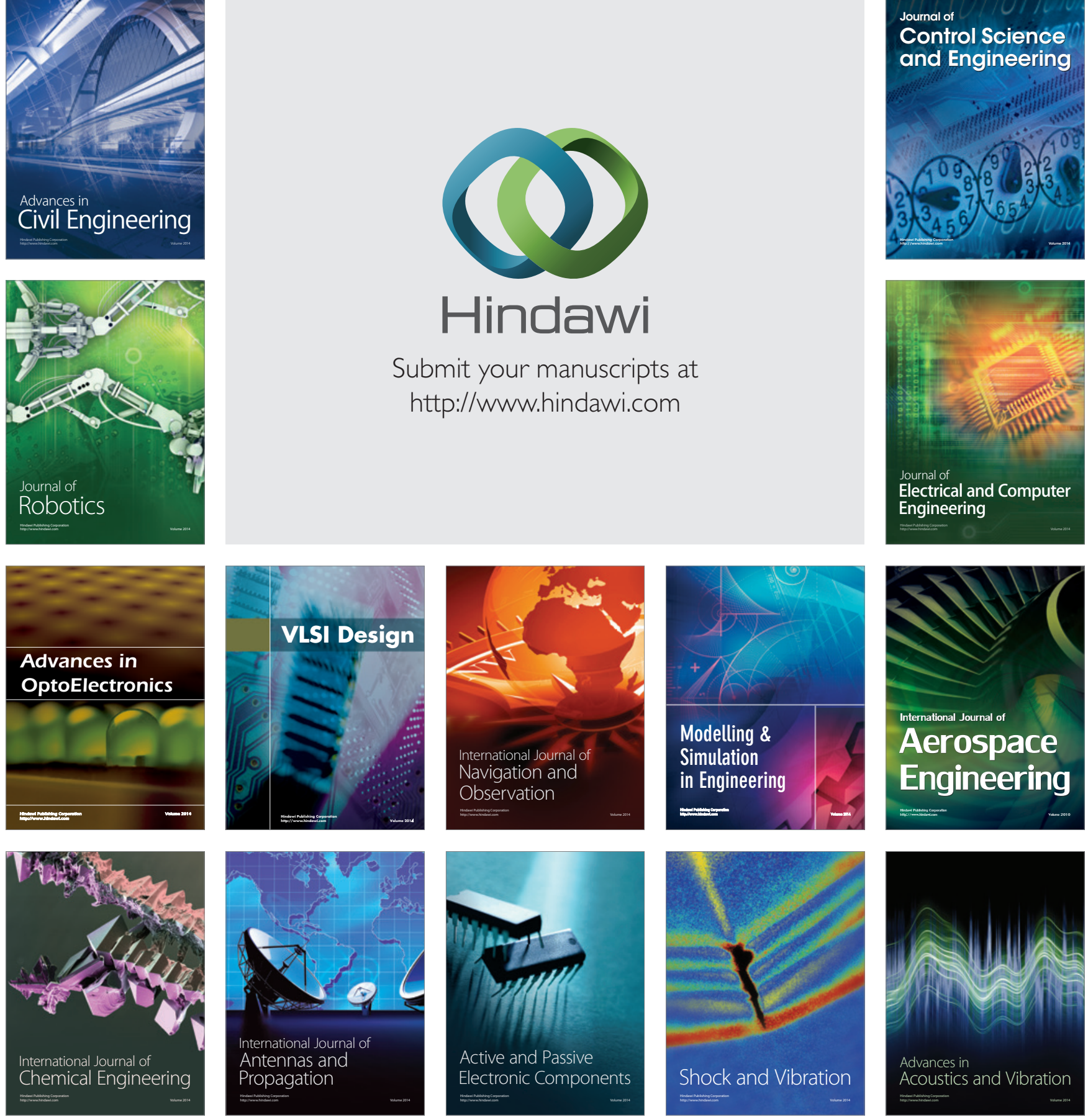